\title{
A culture of ill health: public health or Aboriginality?
}

$\mathrm{M}$ y career in Indigenous health was first ignited in my teenage years as part of an overall desire to "work among my own people". At that point in my life, I never really felt "Aboriginal", owing, in part, to my being of "mixed descent", light-skinned and having been raised in a predominantly white neighbourhood in an urban area. My claim to Aboriginality somehow felt a little inauthentic in light of the public imaginings of Aboriginality that I had been exposed to growing up. My perception of the "real" Aboriginal people were those who possessed dark skin, occupied the remotest parts of our country, and had retained a "pure" and "uncontaminated" Aboriginal culture. Rather naively, I had imagined that I would graduate from university and work with those people, sharing my expert wisdom of health knowledge and, in return, finding a connection with my "true" self - my Aboriginality. Funnily enough, I did achieve my goal of finding myself and my sense of Aboriginality. It was just not in the place, and not in the form, that I had first anticipated several years earlier.

The chronicling of this journey is not meant to be a purely narcissistic endeavour. It revolves around two plights - one personal and one professional - which together describe the disjuncture between the lived experience of being an Aboriginal person and the described experience of Aboriginality that is manifest within public health practices and hampers our ability, as health professionals, to have a meaningful and positive impact on Indigenous health.

It was upon undertaking a degree in Indigenous health that my romanticised ideas of a noble people quickly came crashing down.
I soon learnt that Aboriginal communities were fraught with appalling levels of ill health, disease, despair and dysfunction, a situation that would invoke moral indignation from even the most casual and distant observer. Spurred on by the desire to "save my people", I successfully obtained a rural health scholarship, which (I imagined) would see me stationed within a rural or remote Aboriginal community upon graduation from university. As it turned out, my placement was in a large rural community just 3 hours west of Brisbane. I was initially a little discouraged, as I didn't view that placement as capable of providing me with the personal and professional prestige of having proven myself in a more "authentic" Aboriginal community in some far-flung region of the state. Nonetheless, I still found myself in a place with a sizeable Aboriginal population and a sense of community that I thought had eluded me in all my years growing up in Brisbane.

Upon starting there, I threw myself into the role of Aboriginal health worker, conducting hospital visits to clients, assisting the community medical centre, liaising with non-Indigenous health providers in a cultural brokerage role, and uncritically, week after week, churning out the employer-sanctioned Aboriginal and Torres Strait Islander cultural awareness program. As each workshop went by, I began to notice that there were increasing numbers of local Indigenous community members in attendance, who were interested not so much in teaching others about specific Aboriginal cultural practices and protocols as in learning, sharing and reflecting upon their own experiences as Aboriginal people. Ironically, the task of educating white health professionals about the local Aboriginal community was inadvertently replaced by an ever 


\section{Commitment to family and community among Indigenous people (quotes from a study by Brough et $\mathrm{al}^{4}$ )}

"My wife's cousin rings up from Cairns, said, oh some fellas come down for hospital and they want a place to stay. ... They all say [name's] daughter, down there in Brisbane, you go stay with her anytime. Because dad was always taking in the homeless up in Cairns."

"To me, being involved in the community is something that, if you identify as being Aboriginal, then that's part and parcel of what you give back to it by being involved in your community."

"Weddings, sporting events, NAIDOC Week. Sometimes it can be as little as a performing arts thing. People will turn up ... especially if it's got some Indigenous input in there ... they'll turn up to those events. They're good events because usually people are feeling high in spirit because it's something that ... because there's an Indigenous input (might be Indigenous actors), so they feel proud and good about themselves. This person put on a good play and there's lots of white people there too, so that this white person can see black fellows from a different side and it makes black fellows proud and feel good."

NAIDOC = National Aboriginal and Islander Day Observance Committee

more important task of connecting local Indigenous people with their own experiences, their own histories and their own cultures.

Similarly, most community members appeared less interested in engaging in the traditional health education campaign of our health service, and instead were much more enthused about cultural revival in the form of NAIDOC Week* celebrations, cultural programs for young people, and sharing their own stories of strength and survival. At the time, I was a little troubled by this because, as a health worker, I was meant to be talking up health, not culture. The two seemed to lie in opposition to each other. My supervisor - a non-Indigenous nurse who had never engaged with the local Aboriginal community outside of a nurse-patient relationship at the local hospital - appeared annoyed and concerned about my inability to persuade the community to engage in the "real" health work. Rather than reflect upon the failings of our health service, she, and many of my non-Indigenous colleagues, saw this predicament as just further "evidence" of the passivity, dependency, and non-compliant nature of our mob, which in turn could be explained away as the "real" cause of our ill health. Any efforts on my part to celebrate Aboriginal culture and community were considered a contradiction within our health service, because of the assumed unhealthiness of the Aboriginal experience.

I began to reflect upon the reasons for the Indigenous community's disengagement with health education and started to question the way in which our communities had been constructed within this practice. Within the health care system, no value or worth was attached to being Aboriginal, as the success of the system was measured solely by its ability to bring the health of Indigenous people up to the same level as that experienced by non-Indigenous Australians. Underlying the quest to reduce health inequalities lay first the assignment of inferior status to Aboriginal people within health education programs. Is it actually any wonder, then, that we'd have to beg "Aunty" to come along to a presentation where she was depicted as nothing more than a subset of problems and unhealthy afflictions that could be remedied by simply telling her

\footnotetext{
*NAIDOC (National Aboriginal and Islander Day Observance

Committee) Week is an annual event that celebrates Aboriginal and Torres Strait Islander cultures throughout Australia.
}

to eat better and exercise more? I remember feeling shame about having enticed community members to a workshop for a free feed, only to have them subjected to the paternalism of visiting health professionals, who, by virtue of their occupation alone, assumed they could completely disregard cultural and community protocols and that they were instantaneously authorised to speak to our old people as a parent would to a child. As time went by, I began to feel that health promotion in the form of health education was not empowering, but rather disempowering, to our mob. Under this system, we are seen as nothing more than a group of people who just don't know what is good for us.

And herein lay a strong contradiction between what I had been taught as a health professional and what I had learnt and experienced as an Aboriginal person. Health promotion was, I thought as a health professional, meant to empower people. ${ }^{1}$ Aboriginality, I thought as an Aboriginal person, was about pride, strength, determination and survival - survival of our people, our communities and our cultures. Why then does Indigenous health discursively reverberate around the inadequacies, impairment and hopelessness of our people, families and communities? Yes, sure, the status of Indigenous health is "appalling". We have countless reports, studies, investigations and inquiries to remind us and reinforce the nature and breadth of these problems., ${ }^{2,3}$ But my question remains - so then what? What is left of us that we can draw from to make some improvement to our lot in life? I find it hard to just passively accept, as both an Indigenous person and as a health professional, that Indigenous communities have nothing to bring to the table in efforts to improve our own health.

A few years after I began my rural placement, on returning home to Brisbane, I continued working in the field of Indigenous health, this time in the role of project officer for an urban Indigenous health promotion project that critically challenged these assumptions. It was through this project that I was able to realise how health promotion could equate to more than just health education. Here I was able to work in a manner that sought to uncover and support the true assets of our communities. Perhaps one of the most conspicuous strengths, which community members continually spoke of, was strength in identity - the persistence of Aboriginality within ourselves, our families and our communities. ${ }^{4}$ Here identity was not simply a label or name, a series of health issues, or even a stereotypical depiction, but a very complex, dynamic and fluid entity that provided a resource for everyday living. For instance, a vast number of social resources were derived from large family and community networks, and the values attributed to one's Aboriginal identity produced a reciprocal exchange whereby individuals felt a strong sense of commitment to their community (Box). The result of this participation, such as community organisations and community events, was a source of strength and pride for many of the respondents. It should hardly be surprising, however, that there is something resourceful about Aboriginal identity, given that it has endured over 200 years of active attempts to remove, deny and delegitimise it.

It was here that I made my connection. What resonated most with me was the persistence and diversity of our Aboriginality, which I had witnessed and experienced myself as an Aboriginal person, having lived and worked in both rural and urban Aboriginal communities. All this time, I had been seeking a version of Aboriginality that was simply not mine. So, exactly whose version of Aboriginality was it? My search for answers has led me to undertake a $\mathrm{PhD}$ in Indigenous health, to examine how the concept of Aboriginality has been constructed within public health 
practice. As I've reflected on my own culture as an Aboriginal person, I've been forced to examine the professional culture of public health that I am also a part of. In so doing, I have realised that my own naive and romanticised understanding of the "authentic Aboriginal" was not unique to me. In fact, I have found that these very images are supported and reproduced within much of Indigenous public health practice.

For instance, there has to be some explanation for why the epidemiological gaze in Indigenous health research still disproportionately focuses on rural and remote Aboriginal communities, ${ }^{5}$ when the majority of Aboriginal people reside in urban centres. ${ }^{6}$ One must also question the practice of continually highlighting the health inequalities facing Aboriginal people without explaining the precise causal pathways - thus perpetuating assumptions about "innate characteristics related to 'ethnic' or 'racial' difference". ${ }^{7}$ The perception of Aboriginality as nothing more than a label, a health risk, and predicator of unhealthy behaviours within Indigenous public health practice reinforces stereotypical ideas of Aboriginality, demonises those who possess it, and disconnects Aboriginal people from their own identities in a manner similar to past oppressive policies of colonisation, assimilation, segregation and integration. Critically examining such practices is not just a matter of "political correctness", but a vital step that will have profound and meaningful implications for the health of Aboriginal people.

Such depictions fuel the very racism that creates and compounds health inequality, ${ }^{8-10}$ and may also result in Aboriginal people internalising such negative depictions. ${ }^{11}$ Internalised racism has been linked to increased drug use, behavioural problems, ${ }^{12}$ increased rates of depression and obesity, and lower academic aspirations. ${ }^{13}$ Numerous studies have also demonstrated the association between social status and health inequality, ${ }^{14}$ the relationship between community integration and health, ${ }^{15}$ and the influence of factors such as social exclusion, support, isolation, participation and autonomy. ${ }^{16}$

It has been argued that notions of identity and culture are an important resource for empowering minority or marginalised communities - a goal that accords with the broader global health promotion agenda. ${ }^{17}$ It is not the quantification or authentication of culture by the dominant group, but rather the process of enabling such communities to define, express and represent themselves that is empowering and conducive to better health outcomes. Bearing this in mind, I have sought to develop my research agenda around examining and validating the way in which Aboriginal people define themselves, without the distraction of a predetermined health agenda guiding or hijacking every activity that I engage in.

Importantly, despite my apparent rejection of the way public health is practised and health care delivered to Indigenous people, I do not view my current journey as contradictory to the overall goal of public health practice - which is to improve the health and wellbeing of Aboriginal people. All that differs is the construction of meanings around our own notions of health and Aboriginality. Public health and medicine are themselves cultural practices that have been influenced heavily by the politics of colonialism. ${ }^{18}$ Rather than claiming to be neutral, objective observers of the cultural domain occupied by Aboriginal people, we, as health professionals, need to be prepared to place our own cultural practices under the microscope and examine their effect on the health of Aboriginal people.

For Aboriginal people, health is "not just the physical well being of the individual, but the social, emotional and cultural well being of the whole community ... [and] a matter of determining all aspects of their life, including control over their physical environment, of dignity, of community self esteem and of justice. It is not merely a matter of the provision of doctors, hospitals, medicines or the absence of disease and incapacity. ${ }^{19}$

I am currently conducting my fieldwork, the chosen site of which is itself somewhat poignant. It is not in some far-off exotic location, but just a few suburbs over from where I grew up. Through my journey so far, I have found the strength in my identity as an Aboriginal person, in all of its "inauthenticity", and the strength in my community, in all of its unhealthiness, to see a way forward to improving the health of our people. For me, inherent in the task of improving Indigenous health and in achieving wellbeing as an Indigenous person is providing a space within public health practice and in our own minds that allows us, the "public", to define and redefine our experiences of our identity.

Chelsea J Bond

PhD Student, School of Population Health University of Queensland, Brisbane, QLD

S310979@student.uq.edu.au

1 World Health Organization. Ottawa Charter for Health Promotion. Copenhagen: WHO Regional Office for Europe, 1986.

2 Australian Institute of Health and Welfare and Australian Bureau of Statistics. The health and welfare of Australia's Aboriginal and Torres Strait Islander peoples. Canberra: Australian Government Publishing Service, 2003. (AlHW Cat. No. IHW-6.)

3 Parliament of the Commonwealth of Australia. House of Representatives Standing Committee on Family and Community Affairs. Health is life: report on the Inquiry into Indigenous Health. Canberra: Commonwealth of Australia, 2000. Available at: http://www.aph.gov.au/house/committee/ fca/indhea/reportfinal.pdf (accessed May 2005).

4 Brough M, Bond C, Hunt J. Strong in the city: towards a strength-based approach in Indigenous health promotion. Health Promot J Aust 2004; 15: 215-220.

5 Lake P. What research has been done in Aboriginal health? Aboriginal and Islander Health Worker Journal 1992; 16(2): 8.

6 Australian Bureau of Statistics. Population distribution, Indigenous Australians. Canberra: ABS, 2001. (ABS Cat. No. 4705.0.)

7 Karlsen S, Nazroo J. Agency and structure: the impact of ethnic identity and racism on the health of ethnic minority people. Sociol Health Illness 2002; 24: 1-20.

8 Nazroo J. The structuring of ethnic inequalities in health: economic position, racial discrimination, and racism. Am J Public Health 2003; 93 : 277-285.

9 James SA. Confronting the moral economy of US racial/ethnic disparities. Am J Public Health 2003; 93: 189.

10 Van Ryn M, Fu S. Paved with good intentions: do public health and human service providers contribute to racial/ethnic disparities in health? Am J Public Health 2003; 93: 248-256.

11 Groome H. Towards improved understandings of Aboriginal young people. Youth Studies Australia 1995; 14(4): 17-21.

12 Smith E, Walker K, Fields L, et al. Ethnic identity and its relationship to selfesteem, perceived efficacy and prosocial attitudes in early adolescence. $J$ Adolesc 1999; 22: 867-880.

13 Yancey A, Siegel J, McDaniel K. Role models, ethnic identity and health risk behaviours in urban adolescents. Arch Pediatr Adolesc Med 2002; 156: 5561.

14 Kawachi I, Kennedy K, Lochner K, Prothrow Stith D. Social capital, income inequality and mortality. Am J Public Health 1997; 87: 1491-1498.

15 Berkman L. Social networks and health: the bonds that heal. In: Tarlov A, St Peter R, editors. The society and population health reader. Volume II: A state and community perspective. New York: New Press, 2000.

16 Wilkinson R, Marmot M, editors. Social determinants of health: the solid facts. Copenhagen: World Health Organization, 1998.

17 Williams L, Labonte R, O'Brien M. Empowering social action through narratives of identity and culture. Health Promot Int 2003; 18: 33-40.

18 Thomas D. Reading doctors' writing: race, politics and power in Indigenous health research, 1870-1969. Canberra: Aboriginal Studies Press, 2004.

19 National Aboriginal Health Strategy Working Party. A national Aboriginal health strategy. Canberra: Australian Government Publishing Service, 1989.

(Received 21 Jan 2005, accepted 13 Apr 2005) 